Editorial

\title{
How Do You See Infrastructure? Green Energy to Provide Economic Growth after COVID-19
}

\author{
Idiano D'Adamo ${ }^{1, *(D)}$ and Paolo Rosa ${ }^{2}$ D \\ 1 Department of Computer, Control and Management Engineering, Sapienza University of Rome, \\ Via Ariosto 25, 00185 Rome, Italy \\ 2 Department of Management, Economics and Industrial Engineering, Politecnico di Milano, \\ Piazza L. Da Vinci 32, 20133 Milano, Italy; paolo1.rosa@polimi.it \\ * Correspondence: idiano.dadamo@uniroma1.it
}

Received: 26 May 2020; Accepted: 8 June 2020; Published: 10 June 2020

check for updates

\begin{abstract}
Climate change has determined the deterioration of the ecosystem, but some politicians deny this evidence. There is a relationship between sustainability and resilience, and COVID-19 has demonstrated that life can change quickly. Social and economic disaster share a close bond. Can the realization of a great plan for infrastructure support the planet's rebirth? This is the key role of the green economy.
\end{abstract}

Keywords: COVID-19; economic growth; green infrastructure; resilience; sustainability

\section{Discussion}

Current generations are responsible for offering not only a satisfactory quality of life for future generations, but also for developing opportunities. The globalized world is full of interconnections, where linear management cannot be identified as an appropriate solution. The first step is represented by the definition of territory (local or national) issues, also considering related human expectations. This focus assumes a great relevance when a natural disaster is verified, and our attention is concentrated on this circumstance. However, some problems can also be controlled in regular conditions, in order to strengthen the resilience of infrastructure. We think that the implementation of infrastructure is a great opportunity for an economic development and, at the same time, it is necessary to check the performance of infrastructures during their lifetime. Infrastructure can influence, directly or indirectly, about $72 \%$ of the targets in terms of the Sustainable Development Goals [1]. Following this approach, we suggest some practices that can be implemented in order to improve our lives:

- Carrying out regular maintenance of bridges and viaducts;

- Reducing the amount of imported energy, by favoring the development of green energy;

- Reducing wastewater;

- Favoring the reuse/recycle/recovery of materials;

- Favoring the accessibility of public transport to strategic places, such as hospitals and museums;

- Increasing urban green spaces;

- Applying regular control to prevent landslides and floods;

- Improving energy efficiency;

- Applying measures that can prevent coastal erosion;

- Favoring the connection between transport infrastructure and tourism;

- Favoring digitalization. 
By analyzing these practices, is it possible to create an indicator that is useful for comparing the performance of several countries? The application of multicriteria analysis is able to support this initiative, in which the weight can be determined by a panel of experts. The importance of providing a quantitative analysis that aims to reduce subjectivity during policy choices and increase models of reflexive governance is clear. The implementation of new infrastructure reduces the availability of land use and this aspect must be accurately managed. For this reason, it is requested that spaces occupied by unused infrastructure are recovered, thereby favoring circular practices. Furthermore, the concept of resilience provides value-added for infrastructure and a system's level of reaction changes over time. Both resilience and sustainability are viewed as distinct concepts, but are positively correlated. However, the maximization of efficiencies in sustainable terms can ignore the redundancy, e.g., the lack of parallel or redundant backup systems generates vulnerability in energy delivery systems [2]. Generally, the absence of funds represents a great obstacle for the public sector. Some social and political behaviors, such as Not in My Back Yard (NIMBY) and Not in My Term of Office (NIMTO), are potential issues to consider; the same is also true for some lobbies aiming to conserve their economic monopoly. There are also criminal systems that, thanks to corruption, can occupy relevant market shares by developing speculative investments.

The year 2020 will be remembered for the transmission of COVID-19, which changed the lifestyle of citizens in several parts of the world and caused a considerable number of deaths. The role of medicine is essential in further preventing its transmission and finding a solution. The responsibilities of other fields of science lie in imaging the future by proposing solutions to restart the global economy. The economy has been destroyed by this virus and immediate action is required. Policymakers have a great challenge to cope with. We suggest that they favor the implementation of a great number of new green infrastructures, where consistent investments are also destined for use in the maintenance of existing infrastructure. Certainly, some natural disasters are able to create unquantifiable damage, but the resilience of systems can reduce this damage. Within this context, knowledge becomes power and the future of young generations generates its legitimization. The conjunction between power and legitimization requires authority, and knowledge provides an opportunity to guide the response to this challenge, involving both public and private actors. The non-realization of infrastructure causes a delay that is no longer acceptable. The availability of infrastructure is necessary to generate economic growth and social opportunities, without compromising environmental protection.

The question proposed by [2], in which over-connectivity can cause new types of vulnerabilities, and can influence both sustainability and resilience, is very stimulating and it is probably not possible to provide an absolute response. This work aims to underline the nearness of two terms, "resilience" and "sustainability". The application of green and circular practices does not have the explicit goal of improving the resistance, reliability and redundancy of infrastructure, but their impact is significant in terms of response and recovery (the fourth component of resilience). However, a great benefit is represented by their positive effect on the environment and on climate change. In this way, we can reduce the probability of environmental disasters.

How do we see infrastructure? Are they able to sustain the tradeoff between environmental and human needs? Can quantitative assessments support the transition towards green infrastructure? COVID-19 offers an opportunity to change our vision of infrastructure. A long-term plan is necessary, where public funds and private-public partnerships are required to inject liquidity into the economic system, in which—through the circular flow of money—it is possible to stimulate the demand side.

Funding: This research received no external funding.

Acknowledgments: We are very grateful to Editor-in-Chief Marc A. Rosen, Managing Editor Liv Li and Publishing Manager Franck Vazquez. Furthermore, a special thanks goes to Emanuele Coppola for the graphical abstract.

Conflicts of Interest: The authors declare no conflict of interest. 


\section{References}

1. Thacker, S.; Adshead, D.; Fay, M.; Hallegatte, S.; Harvey, M.; Meller, H.; O’Regan, N.; Rozenberg, J.; Watkins, G.; Hall, J.W. Infrastructure for sustainable development. Nat. Sustain. 2019, 2, 324-331. [CrossRef]

2. Elmqvist, T.; Andersson, E.; Frantzeskaki, N.; McPhearson, T.; Olsson, P.; Gaffney, O.; Takeuchi, K.; Folke, C. Sustainability and resilience for transformation in the urban century. Nat. Sustain. 2019, 2, 267-273. [CrossRef]

(c) (C) 2020 by the authors. Licensee MDPI, Basel, Switzerland. This article is an open access article distributed under the terms and conditions of the Creative Commons Attribution (CC BY) license (http://creativecommons.org/licenses/by/4.0/). 